\title{
Psychological Distress and Signs of Post-Traumatic Stress in Response to the COVID-19 Health Emergency in a Mexican Sample
}

This article was published in the following Dove Press journal:

Psychology Research and Behavior Management

Leivy Patricia

González Ramírez (D)

Reyna Jazmín Martínez Arriaga (iD) ${ }^{2}$

Martha Alicia Hernández-

Gonzalez (D) $^{3}$

José María

De la Roca-Chiapas (iD) ${ }^{4}$

'School of Medicine and Health Sciences, Tecnologico De Monterrey, Guadalajara Campus, Guadalajara, Mexico;

${ }^{2}$ Department of Population Health, Tonalá University Centre, University of Guadalajara, Tonalá, Mexico; ${ }^{3}$ Division head of Health Research, Highly Specialized Medical Unit No, I of the Bajio, Mexican Institute of Social Security (IMSS), León, México; ${ }^{4}$ Department of Psychology, University of Guanajuato, Guanajuato, Mexico
Correspondence: José María De la RocaChiapas

Department of Psychology, University of Guanajuato, Blvd. Puente Milenio I00I,

Fraccion Del Predio San Carlos, León

37670, Guanajuato, Mexico

Tel +52-477-2674900 Ext. 3664

Email josema_delaroca@yahoo.com.mx
Objective: This study aimed to evaluate the psychological impacts of COVID-19 prevention measures, such as social isolation, on a Mexican sample.

Methods: We conducted an online sociodemographic and Impact of Event Scale-Revised (IES-R) survey during the second phase of the COVID-19 outbreak in Mexico to evaluate the presence of psychological distress, signs of post-traumatic stress, and to identify the groups at highest risk in the sample.

Results: Prevalence of psychological distress at moderate or severe levels in the sample were as follows: 943 (22\%) intrusive thoughts, 933 (22.3\%) avoidance, and 515 (12.2\%) hyperarousal. Furthermore, we found the symptoms of clinically significant post-traumatic stress in $1160(27.7 \%)$ of the participants. The variables positively correlated with higher psychological distress were as follows: age (younger), sex (female), employment (employed), relationship status (single), in social isolation, number of days in isolation, the number of people in the household (3-5), and a perception of a high risk of contracting COVID-19, change in routine, engaging in less activity, and loss of income.

Conclusion: During phase 2 of the COVID-19 outbreak in Mexico, we observed the presence of psychological distress and post-traumatic stress symptoms in over a quarter of the population. This investigation may guide mental health interventions and policies towards the groups that are most vulnerable to the impacts of the social and lifestyle changes taking place in Mexico due to COVID-19.

Keywords: coronavirus, mental health, Impact of Event Scale-Revised, intrusive thoughts, stress

\section{Introduction}

According to the World Health Organization (WHO), there are 6 phases of a pandemic. ${ }^{1}$ During the first phase, countries must strengthen their preparations for a pandemic, make a plan of action, and establish epidemiological vigilance in animals and humans. During the second phase of the pandemic, the transmission risk must be reduced as much as possible, such as by rapidly tracing (detecting and notifying) transmission. On the 29th of February 2020, the first case of COVID-19 was confirmed in Mexico. By the 27th of March, the beginning of this investigation, 717 cases, and 12 deaths had been reported. Preventative measures had already been implemented, such as social distancing, hand washing, educational institutions migrated to virtual classes, and large events restricted. By the 9th of April, there were 3441 confirmed cases, 10,105 suspected cases, and 194 deaths in Mexico. ${ }^{2}$ On 
the 1st of April, the closure of non-essential businesses was announced, which caused unemployment and grave economic consequences. ${ }^{3}$ Furthermore, at the social level, there was panic buying, discriminatory behavior, and violence against health professionals and suspected cases; similar to behavior observed in other countries. ${ }^{4}$

To our knowledge, no scientific articles have yet been published on the impact of COVID-19 on mental health in Mexico. However, there is a precedent of H1N1, which was pronounced a pandemic in Mexico at the time. ${ }^{5}$ On that occasion, moderate levels of anxiety, stress, and depression were reported among the Mexican population, particularly among patients and relatives. 5,6

At the international level, patients with COVID-19 may experience fear for their life and infection symptoms, such as fever, hypoxia, and cough. The side-effects of treatment may also worsen anxiety and mental anguish. Furthermore, those in quarantine can experience boredom, loneliness, and anger; ${ }^{7}$ and shame, guilt, or stigma, promoted in part by the media. Psychological anguish has been associated with symptoms of post-traumatic stress disorder (PTSD) and depression. ${ }^{4}$ Many have incurred financial losses and risk unemployment, further intensifying negative emotions. A study in China, conducted during the first phases of the pandemic there, found that $23.2 \%$ of the inhabitants of one province reported stress due changes in their financial situation. ${ }^{8}$

We conducted the study during phase 2 of the COVID19 outbreak in Mexico. The study had the following objectives: to evaluate the presence of psychological distress and symptoms of post-traumatic stress; to compare the variables between groups segmented by sociodemographic and psychosocial characteristics; and to determine the characteristics of the groups at highest risk of psychological distress and post-traumatic stress in the Mexican population.

\section{Materials and Methods}

\section{Study Design}

We conducted a cross-sectional, exploratory study due to the lack of information in the literature on the emotional impact of the initial stages of the COVID-19 health emergency in Mexico. Data was collected from the 27th of March to the 2nd of April 2020. We produced a Google form and asked for volunteers to answer the survey. The initial contacts were mainly students and employees of the University, and the initial contacts shared to their contacts. We obtained 4183 responses. We refined the database using inclusion criteria, selecting only those who lived in Mexico and were over 18 years of age. Outliers were also removed as an elimination criterion, leaving a final sample of 3932 .

\section{Survey}

We created a survey that collected sociodemographic data: sex, age, occupation, marital status, level of education, and location (country). Furthermore, we asked questions related to the pandemic: if they were currently socially isolating or in quarantine due to the COVID-19 health emergency; the number of days in social isolation; the number of people they lived with and were with them during isolation; if they had COVID-19; the level of perceived risk on a scale of $0-10$; where 0 was "I do not think I am at risk" to 10 "I think I may have the virus"; whether the daily routine of the participant had changed due to the preventative measures for COVID-19; if it was less or more than the current activity; and if their economic income had been negatively affected.

We applied the Impact of Event Scale-Revised (IES$\mathrm{R}$ ), which evaluates the emotional distress that accompanies an inherently stressful occurrence, such as violence, abuse, or natural disasters. ${ }^{9}$ The IES-R reports three factors to characterize the emotional distress of an event: intrusive thoughts ( 8 items), avoidance ( 8 items), and hyperarousal (6 items). Given that these factors are symptoms central to PTSD, the revised scale determined cut-off points to suggest the presence of clinically significant PTSD, which is a total score of 35 or more. For the subscales of emotional distress, a score equal to or less than 14 is considered normal, from 15 to 20 as "moderate" distress, and above 20 points, it is "severe." The Cronbach alpha reported for the IES-R is $0.845 .^{10}$ The survey took around five minutes to complete.

\section{Statistical Analysis}

The data were analyzed with the program SPSS v21. We applied the Kolmogorov-Smirnov test and found a nonnormal distribution in the quantitative variables; we applied non-parametric proof. To find the sociodemographic characteristics of the sample, we used frequencies and percentages, or medians, minima, maxima, and percentiles according to the variable type. Later, for the inferential analysis, we turned to the Mann-Whitney $\mathrm{U}$ or chi-squared $\left(\chi^{2}\right)$ tests for post-traumatic stress. For the intrusive thought variables, avoidance, and hyperarousal, we used the Kruskal Wallis o chi-squared $(\chi 2)$ tests. 
For the posthoc analysis, we applied a pairs-based comparison using the Mann-Whitney $U$-test or the chi-squared $(\chi 2)$ tests. We categorized psychological distress variables as "Normal" or "Clinically significant" (grouping "moderate and severe" to conduct a binary regression including the sociodemographic or psychological statistically significant variables, revising the goodness of fit through the Hosmer \& Lemeshow test.

\section{Ethical Considerations}

The project was submitted to the Committee of Ethics and Research of the Highly Specialized Medical Unit [Unidad Medica de Alta Especialidad, UMAE] no, 1 of the Bajio, which is part of the Mexican Institute of Social Security [Instituto Mexicano del Seguro Social, IMSS]. With registration number 2020-1001-042. Individuals who responded to the survey gave their informed consent to participate in the study, which was conducted voluntarily and anonymously through an online form.

\section{Results}

The total sample was 3932 subjects, of whom 3027 (77\%) reported being in social isolation due to the health emergency, and two reported a COVID-19 infection. With regards to routine, $3626(92.2 \%)$ reported that their routine had changed, 2798 (71.2\%) engaged in fewer activities, and 959 (24.4\%) had more activities than before social isolation. In terms of income, $2073(52.7 \%)$ had been negatively affected. We show the sociodemographic characteristics of the sample in Table 1. Age did not have a normal distribution, and greater participation of the younger population was observed, with the following percentiles: $\mathrm{P}_{10}=21, \mathrm{P}_{25}=26, \mathrm{P}_{50}=33, \mathrm{P}_{75}=41$ y $\mathrm{P}_{90}=50$ years.

With regards to the frequency of psychological distress in the sample, $617(14.8 \%)$ reported moderate intrusive thoughts and 326 (7.8\%) severe; for avoidance, 664 (15.9\%) reported a moderate presence and $269(6.4 \%)$ severe; for hyperarousal $411(9.8 \%)$ moderate and 101 $(2.4 \%)$ severe. Concerning the global score, 1160 (27.7\%) had clinically significant symptoms of post-traumatic stress.

We observed statistically significant differences between the factors of psychological distress and posttraumatic stress by comparing groups (see Table 2). In the posthoc tests for intrusive thoughts, we found differences by age group between the normal and moderate levels $(\mathrm{p} \leq 0.001)$ and severe $(\mathrm{p} \leq 0.001)$; in the number of people that were in home isolation between normal and moderate $(\mathrm{p}=0.017)$.
Table I Sociodemographic Characteristics of the Sample

\begin{tabular}{|l|l|l|}
\hline Variable & N (\%) & M (min-max) \\
\hline Sex & & \\
Male & $2928(74.5)$ & \\
\hline Age & $1004(25.5)$ & \\
Occupation & & $33(18-77)$ \\
Employed & & \\
Unemployed & $2738(70)$ & \\
Retired & $1107(28.3)$ & \\
\hline Marital status & $66(1.7)$ & \\
Married & & \\
Free union & $1426(36.3)$ & \\
Single & $376(9.6)$ & \\
Divorced & $1870(47.7)$ & \\
Widowed & $220(5.6)$ & \\
\hline Education & $31(0.8)$ & \\
Did not attend school & $10(0.3)$ & \\
Primary & $15(0.4)$ & \\
Secondary & $92(2.3)$ & \\
High-School & $491(12.5)$ & \\
Bachelor's degree & $2253(57.3)$ & \\
Postgraduate degree & $1065(271)$ & \\
\hline
\end{tabular}

Abbreviations: $\mathrm{N}(\%)$, frequency and percentage; $\mathrm{M}$ (min-max), median (minimum and maximum).

In all the significant cases, younger, female, employed, single, socially-isolating, more days in isolation, a perception of a high risk of contracting COVID-19, a change in routine, less activity and having been economically impacted are risk factors for intrusive thoughts, avoidance, or hyperarousal according to the individual case. Only the group of 3 to 5 persons at home showed a higher risk of intrusive thoughts, hyperarousal, and posttraumatic stress; in comparison to the groups of $0-2$ people, or more than 5 .

Finally, we present the models obtained from the logistic regression in Table 3. For the model of intrusive thoughts, we obtained a value of $\mathrm{p} \leq 0.001$ and an $\mathrm{R}^{2}=0.109$, for avoidance $\mathrm{p} \leq 0.001$ and $\mathrm{R}^{2}=0.064$, for hyperarousal $\mathrm{p} \leq 0.001$ and $\mathrm{R}^{2}=0.088$, finally, for the model of post-traumatic stress $p \leq 0.001$ and an $R^{2}=0.132$. Also, in all the models, we found a good fit with a $p>0.2$ in the Hosmer and Lemeshow test.

\section{Discussion}

We conducted one of the first studies in Mexico on the psychological distress of the COVID-19 health emergency. 


\begin{tabular}{|c|c|c|c|c|c|c|c|c|c|c|c|c|}
\hline \multirow{2}{*}{ 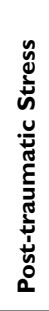 } & \multirow{2}{*}{ 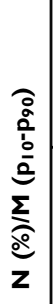 } & 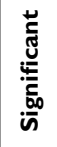 & 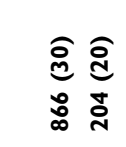 & \multirow[b]{2}{*}{$\begin{array}{l}\overline{8} \\
0.0 \\
\text { पì }\end{array}$} & $\begin{array}{l}\frac{\mathfrak{n}}{1} \\
\frac{1}{2} \\
0 \\
\text { m }\end{array}$ & \multirow[b]{2}{*}{$\begin{array}{l}\text { ò } \\
\dot{0} \\
\text { i. }\end{array}$} & \multirow[b]{2}{*}{ 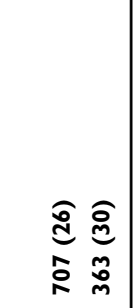 } & \multirow[b]{2}{*}{$\begin{array}{l}n \\
0 \\
0 \\
\text { II }\end{array}$} & 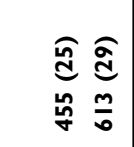 & \multirow[b]{2}{*}{$\begin{array}{l}\overline{0} \\
\dot{0} \\
11 \\
0\end{array}$} & & \multirow[b]{2}{*}{$\begin{array}{l}\overline{8} \\
\vdots \\
\overline{0} \\
0\end{array}$} \\
\hline & & 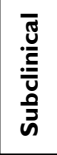 & 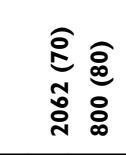 & & $\begin{array}{l}\text { â } \\
\frac{1}{d} \\
\text { du }\end{array}$ & & & & 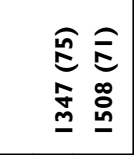 & & & \\
\hline \multirow[b]{3}{*}{ 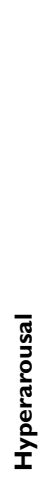 } & \multirow{3}{*}{$\begin{array}{l}\text { à } \\
\frac{0}{0} \\
\frac{0}{0} \\
\Sigma \\
\text { z } \\
\text { z }\end{array}$} & ڤัँ & $\begin{array}{l}\widehat{0} \overline{0} \\
\bar{n}\end{array}$ & \multirow{3}{*}{ 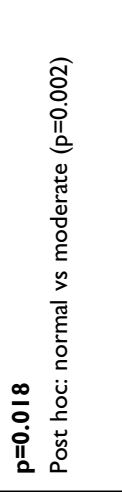 } & \multirow{2}{*}{ 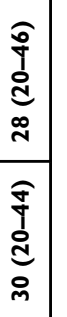 } & \multirow{3}{*}{ 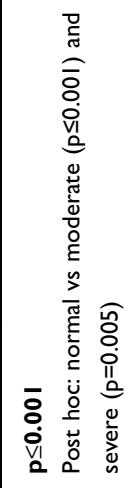 } & 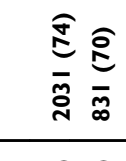 & \multirow{3}{*}{ 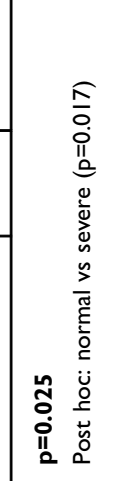 } & $\begin{array}{l}\widehat{a} \\
\hat{m} \\
\text { in }\end{array}$ & \multirow{3}{*}{ 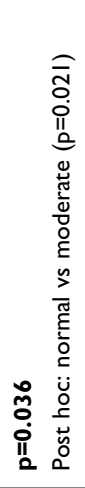 } & 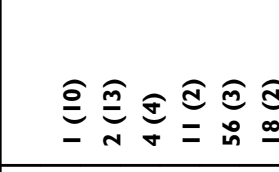 & \multirow{3}{*}{ } \\
\hline & & 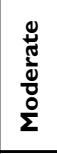 & 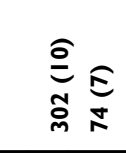 & & & & $\begin{array}{l}d \\
\text { in } \\
\text { in } \\
\end{array}$ & & $\stackrel{\widehat{0}}{\underline{\underline{n}}} \bar{\Xi}$ & & 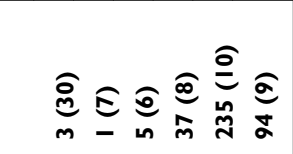 & \\
\hline & & 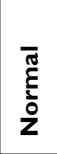 & 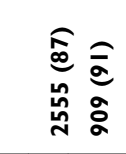 & & $\begin{array}{l}\frac{a}{n} \\
\frac{1}{a} \\
\frac{m}{m}\end{array}$ & & 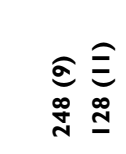 & & 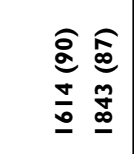 & & 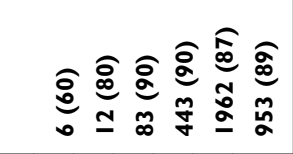 & \\
\hline \multirow[b]{5}{*}{ 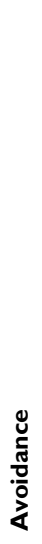 } & \multirow{5}{*}{ 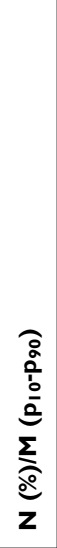 } & ڤัँ & 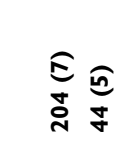 & \multirow{5}{*}{ 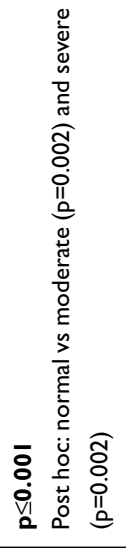 } & 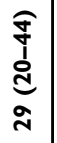 & \multirow{5}{*}{ 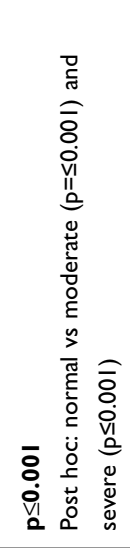 } & 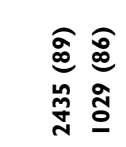 & \multirow{5}{*}{ 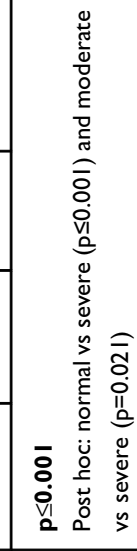 } & 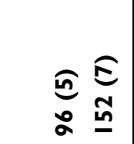 & \multirow{5}{*}{ 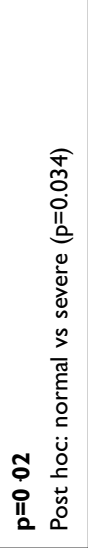 } & 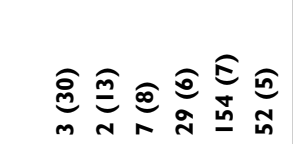 & \\
\hline & & 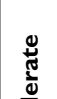 & $\hat{\Xi}$ & & $\frac{\widehat{\alpha}}{\frac{\gamma}{\alpha}}$ & & 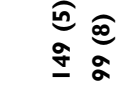 & & $\stackrel{\sqrt[n]{=}}{=}$ & & $\widehat{\underline{\sigma}} \stackrel{\widehat{m}}{=}$ & \\
\hline & & $\frac{\circ}{\Sigma}$ & $\stackrel{\tilde{a}}{\sigma} \stackrel{\mathbb{I}}{\simeq}$ & & $\bar{m}$ & & 气ิ & & సं & & & \\
\hline & & & & & & & \&̊ㅜ & & & & & \\
\hline & & $\begin{array}{l}\overline{\text { बू }} \\
\text { हे } \\
\mathbf{z}\end{array}$ & 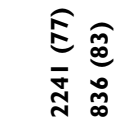 & & 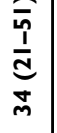 & & 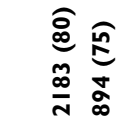 & & 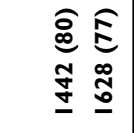 & & 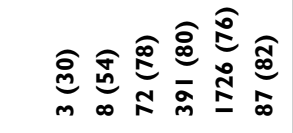 & $\begin{array}{l}\bar{\delta} \\
\dot{0} \\
\text { VI }\end{array}$ \\
\hline \multirow{3}{*}{ 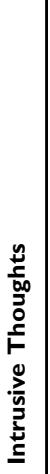 } & \multirow{3}{*}{ 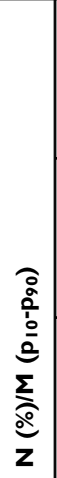 } & ڤँ̀ & 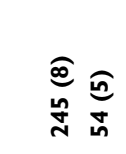 & \multirow{3}{*}{ 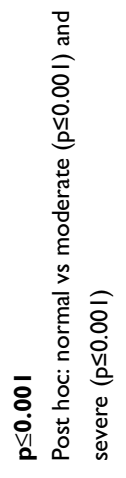 } & 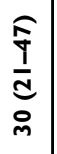 & \multirow{3}{*}{ 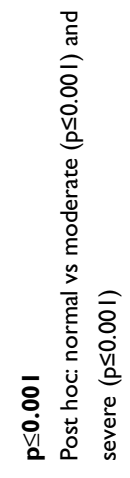 } & $\begin{array}{l}E \widehat{\sigma} \\
\stackrel{0}{0} \\
\stackrel{0}{\sigma}\end{array}$ & \multirow[b]{3}{*}{$\frac{7}{0}$} & 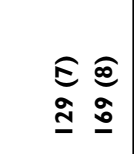 & \multirow{3}{*}{ 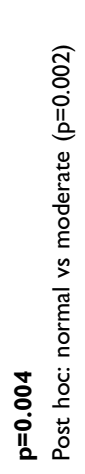 } & 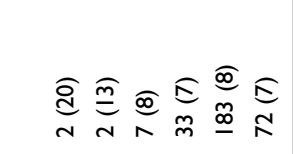 & \multirow{3}{*}{ - } \\
\hline & & 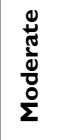 & 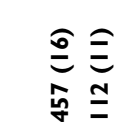 & & $\frac{\frac{a}{y}}{\frac{1}{d}}$ & & 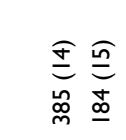 & & 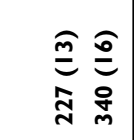 & & 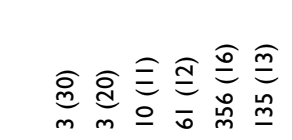 & \\
\hline & & \begin{tabular}{|l}
$\overline{\tilde{\sigma}}$ \\
$\sum_{\bar{z}}$ \\
$\bar{z}$
\end{tabular} & 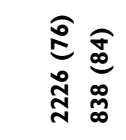 & & 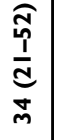 & & 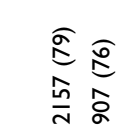 & & 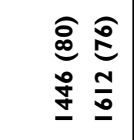 & & 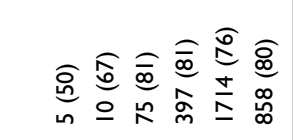 & \\
\hline & & & 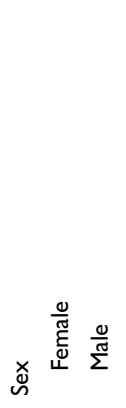 & & $\underset{\leftarrow}{\&}$ & & 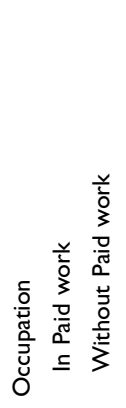 & & 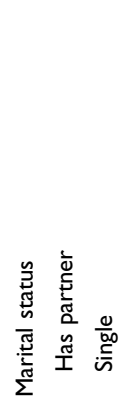 & & 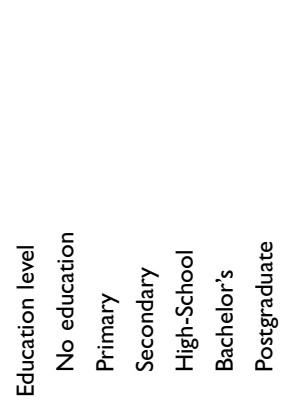 & \\
\hline
\end{tabular}




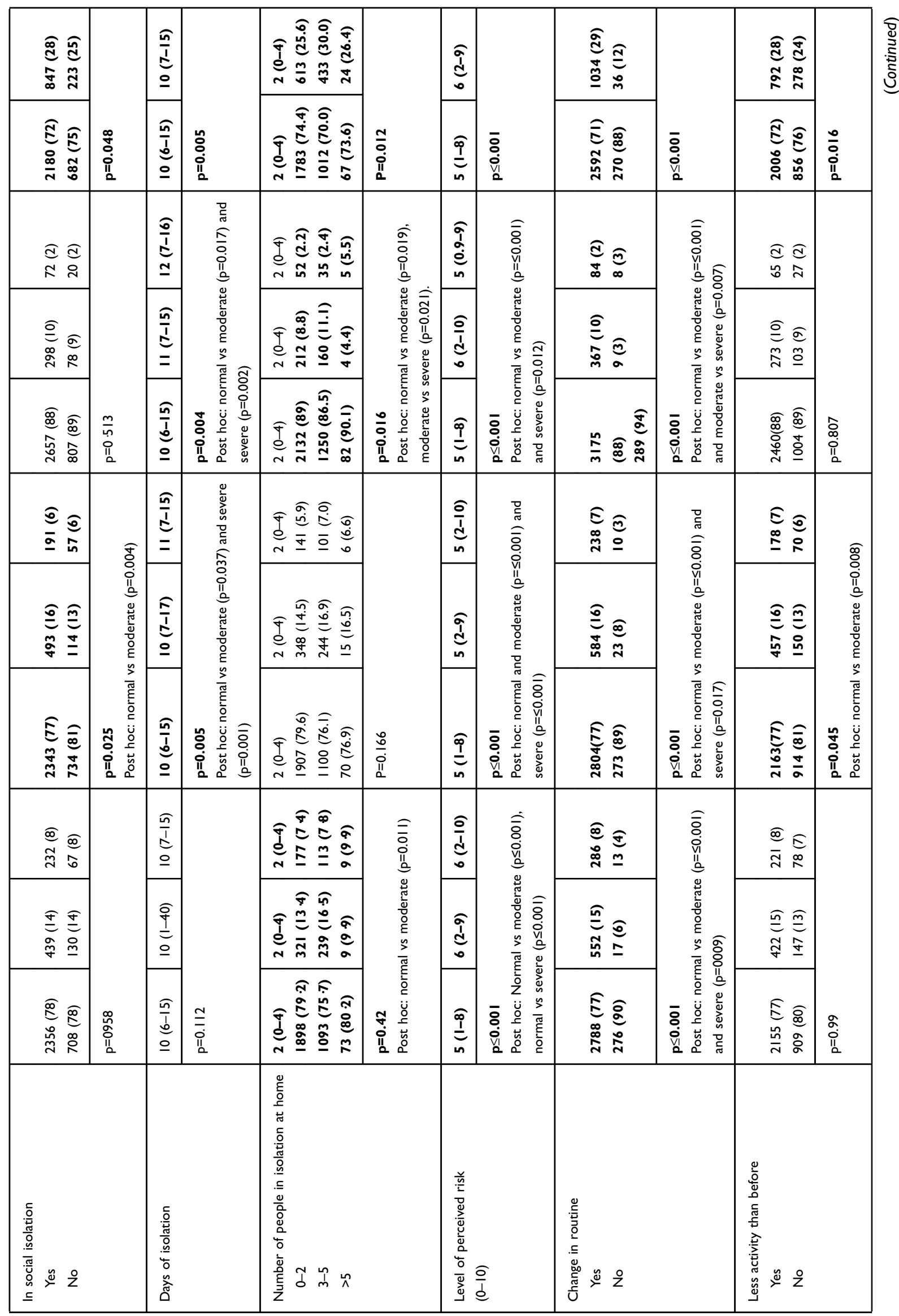




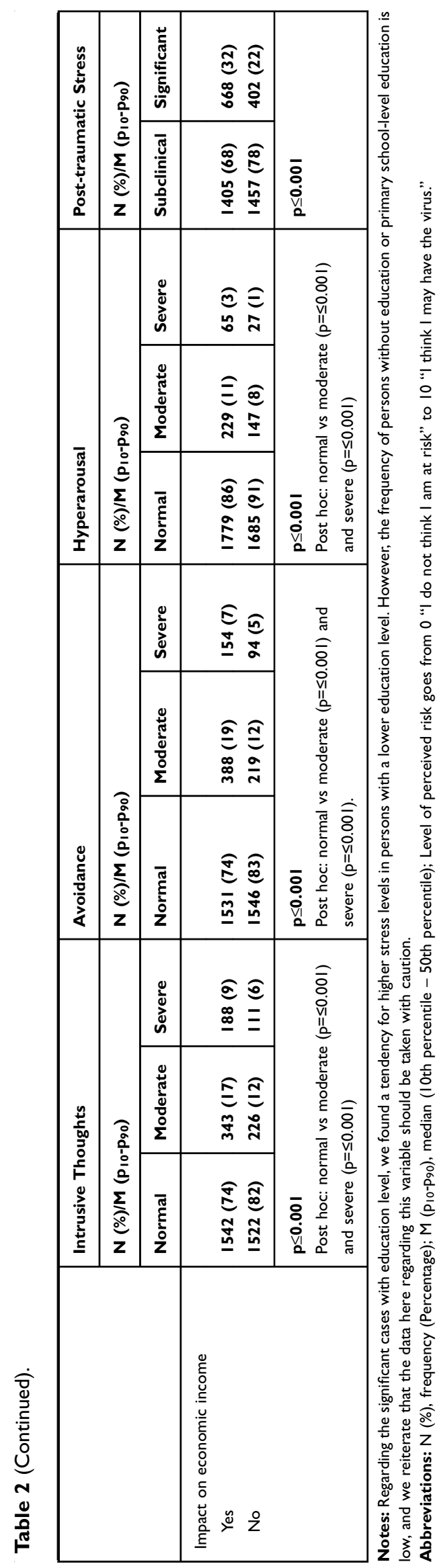

We identified the groups at the highest risk of experiencing intrusive thoughts, avoidance, hyperarousal, and signs of post-traumatic stress within our sample. Risk factors include: age (younger), sex (female), employment (employed), marital status (single), in social isolation, more days in isolation, those with 3-5 people at home, the perception of having a high risk of contracting COVID-19, change in routine, less activity, and loss of income.

A study conducted in China using the same survey (IES-R) found that $24.5 \%$ of participants had minimal psychological impact, $21.7 \%$ moderate and $53.8 \%$ severe, ${ }^{11}$ almost double that of our Mexican sample. Meanwhile, another study found low levels of psychological distress with this scale and only elevated distress in $7.6 \%$ of participants. ${ }^{8}$ The findings are notably distinct, and the timing of measurement could be a factor. At the time of evaluation, the population may not have been wellinformed on the severity of the virus. ${ }^{8}$ The affected communities could be a focal point of stigma and guilt at the international level, limiting commerce, tourism, and increasing emotional distress. ${ }^{11}$ Additionally, in China, despite their efficient measures - they are an example at the international level of group cohesion. Initially, as the epicenter of the pandemic, access to precise information may have been delayed or inconsistent. Therefore, causing uncertainty among the population, while it presented with the highest number of cases. ${ }^{12}$

Individuals develop negative emotions such as anxiety and cognitive disturbance in response to events like the COVID-19 pandemic. ${ }^{14}$ The number of individuals who suffer mental health impacts after similar events tends to be higher than the total with physical injury, and that the effects on mental health last longer. Even so, mental health receives less attention and resources. Furthermore, behaviors such as avoidance could lead to blind conformity. Resulting in individuals ignoring health recommendations and placing themselves at higher risk. ${ }^{14}$ Alternatively, anxiety or extreme fear and stigma derived from the event could also represent a barrier. ${ }^{7}$ Mocciaet al suggest that those who have avoidant characteristics may seem calm in a stressful situation. ${ }^{15}$ However, subjective experience may be the opposite. They suggest that people with anxiety or avoidance are less capable of regulating their emotions. The authors also argue that it is essential to provide strategies to manage or reduce stress.

Concerning sociodemographic characteristics, being female, younger, and single were significant factors. Studies in China have not found differences according to 
Table 3 Logistic Regression of Psychological Distress in Persons in Social Isolation Due to COVID-19

\begin{tabular}{|c|c|c|c|c|c|}
\hline \multirow[t]{2}{*}{ Model } & \multirow[t]{2}{*}{ B } & \multirow[t]{2}{*}{ B } & \multirow[t]{2}{*}{$\mathbf{p}$} & \multicolumn{2}{|c|}{$\begin{array}{l}\text { Confidence } \\
\text { Interval }\end{array}$} \\
\hline & & & & $\begin{array}{l}\text { Lower } \\
\text { Limit }\end{array}$ & $\begin{array}{l}\text { Upper } \\
\text { Limit }\end{array}$ \\
\hline \multicolumn{6}{|l|}{$\begin{array}{l}\text { Intrusive } \\
\text { Thoughts }\end{array}$} \\
\hline Sex & -0.448 & 0.639 & $\leq 0.001$ & 0.523 & 0.781 \\
\hline Age & -0.030 & 0.970 & $\leq 0.001$ & 0.962 & 0.978 \\
\hline $\begin{array}{c}\text { Perceived } \\
\text { infection risk }\end{array}$ & 0.182 & 1.200 & $\leq 0.001$ & 1.163 & 1.238 \\
\hline Change in routine & -1.040 & 0.354 & $\leq 0.001$ & 0.230 & 0.543 \\
\hline Economic income & -0.416 & 0.660 & $\leq 0.001$ & 0.560 & 0.777 \\
\hline \multicolumn{6}{|l|}{ Avoidance } \\
\hline Sex & -0.327 & 0.721 & 0.002 & 0.585 & 0.890 \\
\hline Age & -0.020 & 0.980 & 0.000 & 0.972 & 0.987 \\
\hline Days of isolation & 0.023 & 1.024 & 0.014 & 1.005 & 1.043 \\
\hline $\begin{array}{l}\text { Perceived } \\
\text { infection risk }\end{array}$ & 0.101 & 1.107 & 0.000 & 1.070 & 1.144 \\
\hline Change in routine & -0.702 & 0.495 & 0.006 & 0.301 & 0.814 \\
\hline Economic income & -0.541 & 0.582 & $\leq 0.001$ & 0.490 & 0.693 \\
\hline \multicolumn{6}{|l|}{ Hyperarousal } \\
\hline Age & -0.033 & 0.968 & $\leq 0.001$ & .958 & .978 \\
\hline Days of isolation & 0.035 & 1.035 & 0.003 & 1.012 & 1.059 \\
\hline $\begin{array}{c}\text { Perceived } \\
\text { infection risk }\end{array}$ & 0.184 & 1.202 & $\leq 0.001$ & 1.150 & 1.255 \\
\hline Change in routine & -1.019 & 0.361 & 0.010 & .166 & .785 \\
\hline Economic income & -0.523 & 0.593 & $\leq 0.001$ & .474 & .741 \\
\hline \multicolumn{6}{|l|}{ Post-Traumatic } \\
\hline \multicolumn{6}{|l|}{ Stress } \\
\hline Sex & -0.384 & 0.681 & $\leq 0.001$ & 0.556 & 0.834 \\
\hline Age & -0.036 & 0.965 & $\leq 0.001$ & 0.957 & 0.972 \\
\hline Days of isolation & 0.021 & 1.022 & 0.023 & 1.003 & 1.041 \\
\hline $\begin{array}{c}\text { Perceived } \\
\text { infection risk }\end{array}$ & 0.183 & 1.201 & $\leq 0.001$ & 1.161 & 1.241 \\
\hline Change in routine & -1.115 & 0.328 & $\leq 0.001$ & 0.194 & 0.555 \\
\hline Economic income & -0.546 & 0.579 & $\leq 0.001$ & 0.490 & 0.684 \\
\hline
\end{tabular}

Notes: Model of intrusive thoughts $\mathbf{p} \leq \mathbf{0 . 0 0}, \mathrm{R}^{2}=0.109$; Model of avoidance $\mathbf{p} \leq \mathbf{0 . 0 0 1}, R^{2}=0.064$; Model of hyperarousal $\mathbf{p} \leq \mathbf{0 . 0 0 1}, R^{2}=0.088$; Model of posttraumatic stress $\mathbf{p} \leq \mathbf{0 . 0 0 I}, R^{2}=0.132$.

age. However, studies have observed a more significant risk in students. ${ }^{8,11}$ Higher prevalence of depressive symptoms in the under-35 age group than in the over-35's has also been reported. ${ }^{16}$

Several investigations have found no differences between the sexes in terms of psychological distress. ${ }^{8,17}$ Contrary to our sample, men had a higher risk of intrusive thoughts in one study. ${ }^{8}$ Wang and his collaborators did obtain higher scores in the IES-R in women. ${ }^{11}$ However, they found lower stress, anxiety, and depression than in men. In the Mexican population during the H1N1 pandemic of 2009, it was reported that women, and single people, had a higher risk of stress, anxiety, and depression. ${ }^{5}$

Within the analysis, we found differences by education level; those with a lower level of education had a higher risk of psychological distress. However, there was a low number of responses of people with no education or primary school only. This finding should be further investigated because it has been reported in other studies. ${ }^{11}$

At the time of implementing the survey, the closure of non-essential businesses and companies had not yet been made official in Mexico. Consequently, the number of redundancies or unemployment had not yet reached its maximum peak. However, there was reduced demand for many products and services due to social distancing. Additionally, at least $20 \%$ of the sample is composed of students and another $9 \%$ retirees and homemakers. These factors may explain why the employed experienced higher levels of psychological distress. Torous et $\mathrm{al}^{18}$ warn the next crisis will be mental health from the immediate economic consequences of COVID-19 prevention. The authors argue that the prevalence of psychological disorders and substance abuse could increase. Recent studies have found that concerns about the pandemic impacting their financial situation are related to anxiety in university students. ${ }^{17}$ During the initial phases of the pandemic in China, around $23 \%$ experienced an increased level of stress for financial reasons. ${ }^{8}$

Isolation, the length of isolation, change in routine, particularly with less activity, and 3-5 people in the household, are all associated with higher levels of psychological distress. In the study by Wang et al, ${ }^{11}$ it was reported that $84.7 \%$ of the respondents during the social isolation in China spent on average between 20 to 24 hours at home, and they were worried that their family members would contract COVID-19. Cao et al found a correlation between change in routine and high levels of anxiety. ${ }^{17}$ On the other hand, quarantine and isolation, especially in those who suspect infection, are related to stress, depression, post-traumatic stress disorder (PTSD), insomnia, irritability, anger, and emotional overwhelm. ${ }^{19}$ Without mentioning the effects of the closure of social spaces such as schools, churches, or workplaces that have broken the structures of social support. ${ }^{19}$ Furthermore, activities tend to be more sedentary, prolonged periods in front of screens, and more general lifestyle changes. ${ }^{18}$ In our sample, $92.2 \%$ have changed their routine, and of these $71.2 \%$ engaged in fewer activities than before. Furthermore, we 
find that those who isolated in homes of 3 to 5 people presented more frequently with intrusive thoughts, hyperarousal, and post-traumatic stress. According to data from the National Institute of Statistics and Geography, the average number of inhabitants per dwelling in Mexico is 3.7 people, ${ }^{20}$ there is, on average, one room per person, in contrast with countries such as the United States, which has 2.7 rooms per person. ${ }^{21}$ Over-crowding has been associated with mental health problems. Above all, when accompanied by situations of poverty. ${ }^{22}$

The perception of an elevated risk of contracting the virus was strongly associated with psychological distress. In one study, close to $54 \%$ of those evaluated perceived a moderate or high likelihood of catching the virus. ${ }^{11}$ Some groups reported a higher real and perceived risk. Health professionals presented with high levels of stress, anxiety, depression, insomnia, or even guilt or fear of infecting their families. $4,7,16,23$ The development of psychological morbidities in health workers may be influenced by the lack of social support, communication, maladaptive coping, excessive work, discrimination due to collective panic, and lack of training. ${ }^{4,14}$ Also, those with physical discomfort or a self-perceived poor state of health (and their family members) suffer more significant psychological impacts due to the outbreak. ${ }^{11}$ Especially in response to the media coverage and the social discrimination that has been generated by the pandemic. ${ }^{4,24}$ Sani et $\mathrm{al}^{25}$ mention some psychological interventions proposed in Italy in response to COVID-19. However, these are only offered for healthcare workers.

Our study is one of the first conducted on the psychological impact of COVID-19 in Latin America. Socioeconomic and cultural factors may have influenced our results. Management of COVID-19 is more complicated in the context of a limited health system, a large proportion of the population living in poverty, or with underlying conditions such as diabetes and hypertension. ${ }^{13}$ In Mexico, guidance was issued on emotional care at a distance during COVID$19,{ }^{26}$ such as accompaniment during grief and special situations during the pandemic. ${ }^{27}$ Our findings are novel because they allow us to identify the groups at the highest risk of stress, leading to targeted psychological interventions.

\section{Limitations}

A limitation of the study is the non-random sampling. The results do not reflect the most vulnerable sectors of Mexico, but instead, university staff and students. Secondly, this cross-sectional and anonymous study does not ensure follow-up of the same sample to measure changes in levels of psychological distress at more advanced stages of the health emergency; when more cases are detected, and when the economic havoc that the prevention measures have generated become apparent.

Another limitation is that we did not evaluate the psychological distress of the participants before the pandemic. Although, the IES-R orients the questions to the specific event of interest.

Finally, the results show greater participation of women than men, and although the appropriate statistical analysis was applied, it is prudent to take into account this bias in the interpretation of the higher risk of psychological distress in women.

Despite the above limitations, this study provides invaluable information about psychological distress during the initials phase of the health emergency presented by COVID-19 in Mexico and guides us towards the groups that are potentially most vulnerable for future interventions.

\section{Conclusion}

During the second phase of the COVID-19 pandemic, almost $30 \%$ of the Mexican sample presented with clinically significant symptoms of post-traumatic stress. Considering the number of participants surveyed, we consider this to be a relatively high number. Avoidance was the most common symptom of post-traumatic stress, and included denial of the meanings and consequence of the event, blunted sensation and awareness of emotional numbness. ${ }^{28}$ Based on these findings, we consider that mental health strategies should address the acceptance of the current situation of the pandemic in the population, such as reducing symptoms of post-traumatic stress in general. Strategies could include providing psychoeducation, in addition to psychological techniques for emotional management.

From our results, we can identify the groups with the most significant risk of stress. We consider it essential to orient interventions in mental health to these at-risk groups. Moreover, providing evidence for these at-risk groups may promote their inclusion in health policy.

It is essential to reiterate that we conducted our study during only the second phase of the pandemic. We recommend that studies continue to assess mental health throughout the pandemic, to identify the changes that may occur in the posttraumatic stress incidence of the Mexican population.

\section{Disclosure}

The authors report no conflicts of interest in this work. 


\section{References}

1. World Health Organization. WHO global influenza preparedness plan: the role of WHO and recommendations for national measures before and during pandemics. World Health Organization; 2005. Available from: https://apps.who.int/iris/handle/10665/68998. Accessed Jan 6, 2020.

2. Secretaria DS. Reporte diario 9 de abril 2020; 2020. Available from: https://coronavirus.gob.mx/noticias/. Accessed Sep 4, 2020.

3. Secretaria DS. \#Quedate en casa; 2020. Available from: https://coro navirus.gob.mx/. Accessed Jan 6, 2020.

4. Ho CS, Chee CY, Ho RC. Mental health strategies to combat the psychological impact of COVID-19 beyond paranoia and panic. Ann Acad Med Sing. 2020;49(1):1-3.

5. Elizarrarás-Rivas J, Vargas-Mendoza JE, Mayoral-García M, et al. Psychological response of family members of patients hospitalised for influenza A/H1N1 in Oaxaca, Mexico. BMC Psychiatry. 2010;10 (1):104. doi:10.1186/1471-244X-10-104

6. Jones JH, Salathé M, von Elm E. Early assessment of anxiety and behavioural response to novel swine-origin influenza a(H1N1). PLoS One. 2009;4(12):2-9. doi:10.1371/journal.pone.0008032

7. Xiang YT, Yang Y, Li W, et al. Timely mental health care for the 2019 novel coronavirus outbreak is urgently needed. Lancet Psychiatry. 2020;7(3):228-229. doi:10.1016/S2215-0366(20)30046-8

8. Zhang Y, Ma ZF. Impact of the COVID-19 pandemic on mental health and quality of life among local residents in Liaoning Province, China: a cross-sectional study. Int $J$ Environ Res Public Health. 2020;17(7):2381. doi:10.3390/IJERPH17072381

9. Tiemensma J, Depaoli S, Winter SD, et al. The performance of the IES-R for Latinos and non-Latinos: assessing measurement invariance. PLoS One. 2018;13(4):e0195229. doi:10.1371/journal. pone.0195229

10. Costa Requena G, Gil Moncayo FL. Propiedades Psicométricas De La Escala Revisada Del Impacto Del Evento Estresante (Ies-R) En Una Muestra Espanola De Pacientes Con Cancer. Análisis y Modificación de Conducta. 2007;33(149):149. doi:10.33776/amc. v33i149.1218

11. Wang C, Pan R, Wan X, et al. Immediate psychological responses and associated factors during the initial stage of the 2019 coronavirus disease (COVID-19) epidemic among the general population in China. Int J Environ Res Public Health. 2020;17(5). doi:10.3390/ ijerph17051729

12. Li S, Wang Y, Xue J, et al. The impact of covid-19 epidemic declaration on psychological consequences: a study on active weibo users. Int J Environ Res Public Health. 2020;17(6). doi:10.3390/ ijerph17062032

13. Litewka S, Heitman E. Latin American healthcare systems in times of pandemic. Dev World Bioeth. 2020;1-5.

14. Li W, Yang Y, Liu Z-H, et al. Progression of mental health services during the COVID-19 outbreak in China. Int J Biol Sci. 2020;16 (10):1732-1738. doi:10.7150/ijbs. 45120
15. Moccia L, Janiri D, Pepe M, et al. Affective temperament, attachment style, and the psychological impact of the COVID-19 outbreak: an early report on the Italian general population. Brain Behav Immun. 2020;87:75-79. doi:10.1016/j.bbi.2020.04.048

16. Huang Y, Zhao N. Generalized anxiety disorder, depressive symptoms and sleep quality during COVID-19 epidemic in China: a web-based cross-sectional survey. MedRxiv. 2020. doi:10.1101/ 2020.02.19.20025395

17. Cao W, Fang Z, Hou H, et al. The psychological impact of the COVID-19 epidemic on college students in China. Psychiatry Res. 2020;287:112934. doi:10.1016/j.psychres.2020.112934

18. Torous J, Jän Myrick K, Rauseo-Ricupero N, Firth J. Digital mental health and COVID-19: using technology today to accelerate the curve on access and quality tomorrow. JMIR Ment Health. 2020;7(3): e18848. doi: $10.2196 / 18848$

19. Jung SJ, Jun JY. Mental health and psychological intervention amid COVID-19 outbreak: perspectives from South Korea. Yonsei Med J. 2020;61(4):271. doi:10.3349/ymj.2020.61.4.271

20. INEGI. Vivienda; 2015. Available from: https://www.inegi.org.mx/ temas/vivienda/. Accessed Jan 6, 2020.

21. OECD. Better life index; 2020. Available from: http://www.oecdbet terlifeindex.org/es/countries/mexico-es/. Accessed Jan 6, 2020.

22. Pepin C, Muckle G, Moisan C, et al. Household overcrowding and psychological distress among Nunavik Inuit adolescents: a longitudinal study. Int J Circumpolar Health. 2018;77(1):1-11. doi:10.1080/ 22423982.2018.1541395

23. Liu S, Yang L, Zhang C, et al. Online mental health services in China during the COVID-19 outbreak. Lancet Psychiatry. 2020;7(4):e17e18. doi:10.1016/S2215-0366(20)30077-8

24. Bo H-X, Li W, Yang Y, et al. Post-traumatic stress symptoms and attitude toward crisis mental health services among clinically stable patients with COVID-19 in China. Psychol Med. 2020:1-7. doi:10.1017/s0033291720000999.

25. Sani G, Janiri D, Di Nicola M, et al. Mental health during and after the COVID-19 emergency in Italy. Psychiatry Clin Neurosci. 2020;74 (6):372. doi:10.1111/pen.13004

26. Álvarez Martínez J, Andrade Pineda C, Vieyra Ramos V et al. Manual operativo del Curso Emergente para la Brigada de Atención Psicoemocional y Psicosocial a distancia durante la pandemia de la COVID- 19 en México. Instituto Nacional de Psiquiatría, Ramón de la Fuente Muñiz; 2020. Available from: http://inprf.gob.mx/ensenanzanew/ archivos/2020/manual_brigadas_2020.pdf. Accessed July 12, 2020.

27. Manual operativo del curso para el acompañamiento del duelo en situaciones especiales durante la pandemia de la COVID-19 en México. Instituto Nacional de Psiquiatría, Ramón de la Fuente Muñiz; 2020. Available from: http://inprf.gob.mx/ensenanzanew/ archivos/2020/manual_duelo.pdf.

28. Horowitz M, Wilner $\bar{N}$, Alvarez W. Impact of event scale: a measure of subjective stress. Psychosom Med. 1979;41(3):209-218. doi:10. 1097/00006842-197905000-00004
Psychology Research and Behavior Management

\section{Publish your work in this journal}

Psychology Research and Behavior Management is an international, peer-reviewed, open access journal focusing on the science of psychology and its application in behavior management to develop improved outcomes in the clinical, educational, sports and business arenas. Specific topics covered in the journal include: Neuroscience, memory and decision making; Behavior modification and management; Clinical applications; Business and sports performance management; Social and developmental studies; Animal studies. The manuscript management system is completely online and includes a very quick and fair peer-review system, which is all easy to use. Visit http://www. dovepress.com/testimonials.php to read real quotes from published authors. 